\begin{tabular}{ll} 
Bentham open & The Open Dentistry Journal \\
CrossMark & Content list available at: www.benthamopen.com/TODENTJ/ \\
\hline
\end{tabular}

RESEARCH ARTICLE

\title{
Peri-Implant Bone Loss at Implants Placed in Preserved Alveolar Bone Versus Implants Placed in Native Bone: A Retrospective Radiographic Study
}

\author{
Johann Bui Quoc ${ }^{*}$ Aurélie Vang and Laurence Evrard \\ Department of Dentistry, Oral and Maxillofacial Surgery, Orthodontics, Stomatology, Erasme Hospital, Université \\ libre de Bruxelles, Brussels, Belgium
}

Received: April 12, 2018

Revised: June 20, 2018

Accepted: July 6,2018

\begin{abstract}
:
Objectives:

The aim of our study was to compare peri-implant bone loss at implants placed in alveolar sockets filled with a particulate allogenous bone graft (DFDBA 300-500 $\mu \mathrm{m}$ ) and platelet concentrates versus at implants placed in the native bone.
\end{abstract}

\section{Materials and Methods:}

A retrospective clinical study was performed. A total of 84 patients were included with 247 implants for the restoration of mono and pluri-radicular teeth: 169 implants in native bone and 78 in socket-grafted bone. The peri-implant bone loss was measured by 2 independent operators at 6 and 12 months.

Results:

The overall mesial and distal peri-implant bone losses were $0.9 \pm 0.7 \mathrm{~mm}$ and $0.9 \pm 0.8 \mathrm{~mm}$ at 6 months, respectively, and $1 \pm 0.65$ $\mathrm{mm}$ and $1.2 \pm 0.9 \mathrm{~mm}$ at 12 months, respectively. In the tested group, the bone loss was $0.8 \pm 0.8 \mathrm{~mm}$ at 6 months and $1.2 \pm 0.9 \mathrm{~mm}$ at 12 months. In the control group, the bone loss was $1.0 \pm 0.7 \mathrm{~mm}$ at 6 months and $0.95 \pm 0.6 \mathrm{~mm}$ at 12 months. There were no statistically significant differences in bone loss between the two groups. Taking both groups together, there were no statistically significant difference in bone loss between patients with or without histories of periodontitis, but there was a statistically significant difference in bone loss between the mandible and maxilla as well as between unitary and total edentations and between partially and total edentulous patients.

\section{Conclusion:}

At 6 and 12 months, the peri-implant bone loss in sockets preserved with DFDBA and platelet concentrates was similar to the periimplant bone loss in native bone.

Keywords: Allograft, Alveolar preservation, DFDBA, Platelet concentrates, PRF, Mandibular canal.

\section{INTRODUCTION}

Currently, dental implants are regularly included in the overall treatment plan for patients. Implant success is defined by criteria that have changed over time. The criteria commonly accepted in implantology were originally defined by Albrektsson and colleagues in 1986 [1].

According to these authors, the individual implant had to be immobile when it was clinically tested, the radiography could not show a radiolucent space around the implant, the bone loss had to be less than $1.5 \mathrm{~mm}$ after the first year of

\footnotetext{
"Address correspondence to the author at the Department of Dentistry, Oral and Maxillofacial Surgery, Orthodontics, Stomatology, Hospital Erasme, Université libre de Bruxelles, 808 Route de Lennik, B-1070 Brussels, Belgium; Tel: 00-32-475.30.58.10; E-mail: jbuiquoc@ulb.ac.be
} 
setting function and $0.2 \mathrm{~mm}$ per year thereafter, the implant had not to be responsible for persistent and/or irreversible signs and symptoms, such as pain, infection, nerve damage, paresthesia or penetration into the mandibular canal, and it was necessary that the minimum success rate of implants was $85 \%$ at the end of a period of 5 years and $80 \%$ at the end of a period of 10 years [1].

These success criteria were majored by Smith and Zarb [2]: the implant should not cause damage to the roots of adjacent teeth or perforate the mandibular canal or maxillary sinus or nasal cavity. The authors indicated also that the absence of radiolucent edging on the mesial and distal sides of the implant did not exclude the possibility of bone loss or lack of osteointegration on vestibular and/or lingual parts. They stated also that bone loss should be less than 1.5 to $1.6 \mathrm{~mm}$ at the end of the first year of function and $0.2 \mathrm{~mm}$ per year thereafter.

In a more recent article [3], the authors emphasized that, to indicate success, periodontal criteria should be carefully considered: peri-implant pocket depth should be less than $3 \mathrm{~mm}$ at probing, and there should be an absence of blood and/or pus on probing, an absence of swelling and receding gums, a low plaque index and a width of the attached mucosa greater than $1.5 \mathrm{~mm}$. For other authors [4, 5], peri-implant pocket depth should be less than 5 or $6 \mathrm{~mm}$ to indicate success. Although gingival inflammation (mucositis) is not an implant failure criterion, it is nevertheless important to treat it so that it does not develop in peri-implantitis causing peri-implant pockets and bone loss [2, 4]. Compared with initial papers that were focused on success, the aesthetic and personal evaluation of the patient's appearance with his or her prosthesis has become one of the most important success criterions [3]. It has been said that, in the future, a common index of aesthetic criteria should be established by clinicians $[2,3,6]$.

Our study aimed to evaluate peri-implant bone loss over time, which is known to be influenced by various factors. Hygiene is the preponderant factor. The accumulation of plaque around implants is responsible for inflammation of peri-implant soft tissue, which can lead to bleeding and/or pus on probing and bone loss.

Therefore, the practitioner must ensure adequate forms of supra-structures to allow for easy cleaning to ensure longterm implant preservation [7 - 12]. Patients with a history of periodontal disease or with active periodontitis have increased the risk of peri-implantitis and therefore of bone loss. It is therefore essential to treat periodontitis prior to implant placement to avoid bacterial translocation [7, 9 - 12].

In several studies, there has been a correlation between the consumption of tobacco and marginal bone loss. Thus, it is important to encourage patients to stop smoking before they receive their implants [7, 9 - 12]. Studies aiming to determine if there is an association between diabetic patients with poor glycemic control and the occurrence of periimplantitis have reported contradictory results $[7,9,12]$. Nevertheless, there is a consensus on the fact that subjects with a good metabolic control remain at low risk for implant failure [7, 9, 12]. Also contradictory have been the results of studies on the relationships between the roughness of implants and bone loss [7, 12]. There is a link between daily consumption of more than $10 \mathrm{~g}$ of alcohol per day and loss of peri-implant marginal bone [6, 7]. Other factors that could have an influence on peri-implant bone are endodontic infections on neighboring teeth $[6,13]$ and occlusal overload $[10$ - 12].

Anaerobic gram-negative bacteria grow around the implant and their interaction with the biofilm can lead to their aggregation and to the destruction of the peri-implants tissues. When a peri-implantitis is diagnosed, a higher amount of micro-organisms is present and most of them are anaerobic $[12,14,15]$.

Tooth extraction is followed by physiological alveolar bone resorption, which is irreversible and can reach up to $40 \%$ in height and $60 \%$ in width with great loss occurring within the 3 months after extraction [16]. Insufficient bone can compromise dental implant treatment with a risk of injuring anatomical structures [17]. Therefore, adequate alveolar ridge preservation is essential for aesthetical outcomes and correct implant placement [18].

Among the biomaterials used for post-extraction alveolar filling [19 - 23], allogenic bone has been described as a suitable material. In the particulate form, Freeze-Dried Bone Allograft (FDBA) and Demineralized Freeze-Dried Bone Allograft (DFDBA) have been used in dental surgery and alveolar ridge preservation technique [23 - 27]. It has been shown that, when used in post-extraction sockets, allografts have positive effects on height preservation [23, 24]. In a histological study of alveolar preservation [26], it was shown that DFBDA led to a statistically significantly greater mean percentage of newly formed vital bone than FDBA.

Platelet concentrates (platelet-rich-fibrin) are obtained by centrifugation of blood, following a method first described by Choukroun and colleagues [28]. These materials contain high concentrations of growth factors [29] (PDGF, TGF- $\beta$, IGF and VEGF), and inflammatory molecules (IL-1 $\beta$, IL-4, IL-6 and TNF- $\alpha$ ), and they could enhance 
the healing process [30], possibly leading to better bone repair and regeneration [30, 31]. It has been shown that platelet concentrates accelerate the healing of dermal soft tissue [32] and of the oral mucosa in cases of extraction [33, 34]. It remains unclear whether they are able to accelerate bone healing and influence the bone quality of extraction sockets, although it has been suggested in some studies $[35,36]$. In oral surgery, the benefits in the treatment of periodontal defects with a combination of platelet concentrates and DFDBA have been shown [37].

To our knowledge, there is no previous study comparing peri-implant bone loss at implants placed in preserved sockets with DFDBA and platelet concentrates and peri-implant bone loss at implants placed in the native bone. The aim of our study was to compare this null hypothesis being that there was no difference between the two.

\section{MATERIALS AND METHODS}

A retrospective clinical study, based on the files and radiographs of patients, was conducted (Ethics Committee of Erasme Hospital-ULB. Approval P2013 / 296).

\subsection{Patient Selection}

Patients of our clinic who had received implant following a one stage technique, preceded or not by post-extraction alveolar bone preservation using allograft (DFDBA: 300-500 $\mu \mathrm{m}$ ), and platelet concentrates were selected (Table 1). Patients were restricted to those with implant prosthetics in progress or completed, allowing for radiological monitoring.

The following exclusion criteria were applied: the consumption of 20 or more cigarettes/day, taking of bisphosphonates, ongoing chemotherapy treatment, high-risk heart disease and/or an uncontrolled systemic or periodontal disease.

The characteristics considered to be risk factors were collected from patient data to allow for an analysis by subgroups. The study included a total of 84 patients. Among these patients, 247 implants $\left({ }^{\circledR}\right.$ Nobelbiocare Speedy Groovy in the maxilla and MKIII in the mandible) were placed. Among these implants, 169 were inserted into the native bone (control group), and 78 were placed in the post-extraction alveolar bone filled with allograft and platelet concentrates (test group) (Table 1). These 247 implants restored 84 mono-radicular teeth and 163 pluri-radicular teeth.

Table 1. Table of effective.

\begin{tabular}{|c|c|c|}
\hline- & N Implants & N Patients \\
\hline Total & 247 & \\
\cline { 1 - 2 } 8 & 84 \\
\hline Native bone (control group) & 169 & \\
\hline DFDBA $(300-500 \mu \mathrm{m})+$ platelet concentrates (test group) & 78 & \\
\hline
\end{tabular}

In the test group, the technique used to optimize the maintenance of the post-extraction alveolar bone volume, combining a mixture of particulate bank bone (allograft: DFDBA 300-500 $\mu \mathrm{m}$ ) with platelet concentrates, was applied. At the time of the beginning of extractional surgery, platelet concentrates (platelet-rich fibrin) were obtained by centrifugation of blood samples of the patient in $10 \mathrm{ml}$ tubes with no adjuvant anticoagulant, centrifuged at $3000 \mathrm{rpm}$ for 10 minutes, following a protocol described previously [22]. Parts of the centrifuged blood rich in platelets (called buffy-coats) were cut and mixed with $300-500 \mu \mathrm{m}$ of particulate DFDBA (2 buffy-coats $/ 1.75 \mathrm{~cm}^{3}$ DFDBA $300-500$ $\mu \mathrm{m})$. Parts rich in fibrin were pressed manually between gauze to obtain autologous rich-in-fibrin membranes. Atraumatic extractions were realized, and immediately afterward, filling of the socket was performed with the mixture of DFDBA and platelet concentrates. Closure of the sockets was performed using autologous fibrin membrane to cover the filled socket and polyglactin absorbable sutures to close (Vicryl $\left.{ }^{\circledR} 3 / 0\right)$.

The implants were placed after a period of 3 to 6 months of healing, according to a surgical procedure in one stage. Implants were placed in each case with the neck precisely positioned at the level of the bone.

\subsection{Measurement Methods of Peri-Implant Bone Loss}

Peri-implant bone loss was measured in the mesial and distal aspects of each implant on panoramic radiographs or on retro-alveolar radiographs with an orthogonal incidence of the X-ray (Fig. 1), at a period of 6 months after placement of the implant and also after a period of 12 months for all patients who presented for follow-up appointments. These measurements were performed using the "Romexis" X-ray software with accuracy $\pm 0.1 \mathrm{~mm}$. Measurements were performed by two independent operators. 


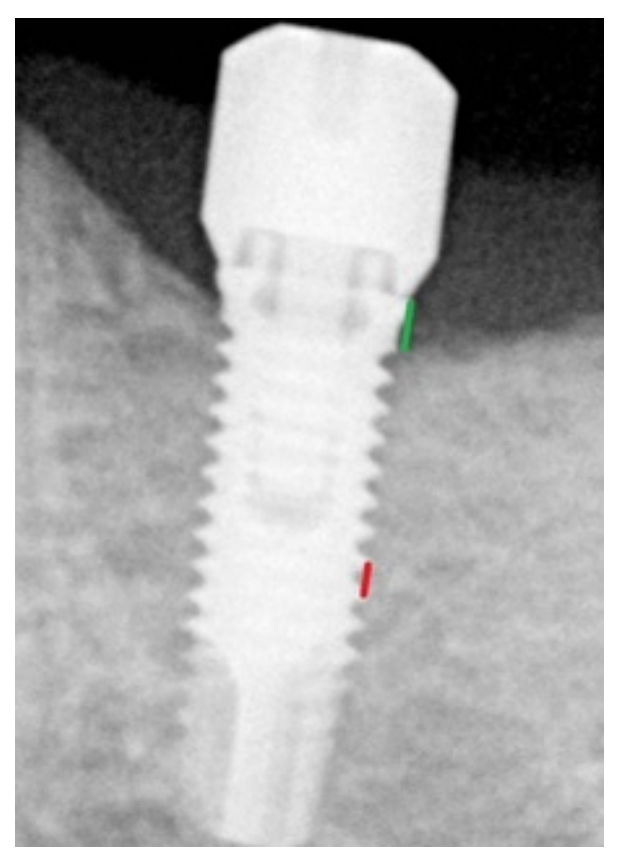

Fig. (1). Method of bone loss measurements and of calibration on radiographs. Bone loss (1) was defined as the distance between the top of the neck of the implant (arrow) and bone level in contact with implant $\left(^{*}\right)$. Each measurement was calibrated by a rule of three, knowing distance between two threads of the implants (2).

Each radiograph was calibrated. The two types of implants ( ${ }^{\circledR}$ Nobelbiocare Speedy Groovy in the maxilla and MKIII in the mandible), and their diameters and lengths were recorded. Depending on these parameters, the distance between two threads of the implant possessed a determined value that then allowed for scaling of the radiograph by a rule of three. The peri-implant bone loss could thus be calculated precisely. This loss was defined as the distance between the neck of the implant and the bone level in contact with the implant (Fig. 1). No radiograph was performed just after the placement of the implant because implants had been placed in each case with neck precisely positioned at the level of the bone. Given the retrospective nature of the study, we were unable to record the bleeding on probing nor the pocket probing deep.

\subsection{Statistical Analysis}

SPSS statistical software, version 22, was used. The peri-implant bone losses are presented as the means and standard deviations.

The size of our sample allowed us to use parametric tests. Student's t-test was performed to compare the periimplant bone loss in the test group and in the control group at 6 months and 12 months. Student's t-test was used to determine whether there was a statistically significant difference between the peri-implant bone loss in the maxilla compared to the mandible in the patients with a history of periodontitis now stabilized compared with patients without a periodontal history at periods of 6 months and 12 months among the separate groups: native bone, allograft and global groups.

ANOVA was performed to compare the peri-implant bone loss among the unit, partial, total edentation sites at 6 months and 12 months in the three groups mentioned above.

A pairwise comparison was then performed using the Games-Howell or Bonferroni tests depending on whether we rejected or not the equality of variances.

Finally, we compared the average measurements of the two independent operators by the calculation of correlation coefficients.

A $p$-value $<0.05$ was considered to indicate a significant statistically level. 


\section{RESULTS}

\subsection{Inter-operator Concordance}

Regarding the concordance between the two independent operators, the correlation coefficients near 1 indicated a good degree of association between the measurements of both manipulators (Table 2).

Table 2. Comparison of the peri-implant bone loss between the two independent operators with correlation coefficients.

\begin{tabular}{|c|c|c|c|c|c|}
\hline \multicolumn{2}{|r|}{-} & $\mathbf{N}$ & Mean (mm) & SD (mm) & Correlation Coefficients \\
\hline \multirow{2}{*}{ Pair 1} & Rx 6 Mes J & 212 & 0.9255 & 0.7352 & \multirow{2}{*}{0.898} \\
\hline & Rx 6 Mes A & 212 & 0.8901 & 0.7287 & \\
\hline \multirow{2}{*}{ Pair 2} & $\mathrm{Rx} 6$ Dis $\mathrm{J}$ & 212 & 0.9252 & 0.7623 & \multirow{2}{*}{0.941} \\
\hline & Rx 6 Dis A & 212 & 0.8807 & 0.7458 & \\
\hline \multirow{2}{*}{ Pair 3} & Rx 12 Mes J & 212 & 1.0363 & 0.6542 & \multirow{2}{*}{0.812} \\
\hline & Rx 12 Mes A & 73 & 0.9808 & 0.6434 & \\
\hline \multirow{2}{*}{ Pair 4} & $\mathrm{Rx} 12$ Dis J & 73 & 1.1260 & 0.7434 & \multirow{2}{*}{0.947} \\
\hline & $\mathrm{Rx} 12$ Dis A & 73 & 1.0178 & 0.7036 & \\
\hline
\end{tabular}

\subsection{Peri-Implant Bone Loss}

Of the 212 implants evaluated at 6 months, the overall peri-implant bone loss was $0.9 \pm 0.7 \mathrm{~mm}$ at the mesial level and $0.9 \pm 0.8 \mathrm{~mm}$ at the distal. At 12 months, the overall peri-implant bone loss on 73 implants was $1 \pm 0.65 \mathrm{~mm}$ at the mesial level and $1.1 \pm 0.7 \mathrm{~mm}$ at the distal level (Table 3).

Table 3. Peri-implant bone loss in the global group (test and control groups taken together).

\begin{tabular}{|c|c|c|c|c|}
\hline- & Rx 6 Més & Rx 6 Dis & Rx 12 Més & Rx 12 Dis \\
\hline N & 212 & 212 & 73 & 73 \\
\hline Mean $(\mathrm{mm})$ & 0.925 & 0.925 & 1.036 & 1.126 \\
\hline SD $(\mathrm{mm})$ & 0.735 & 0.762 & 0.654 & 0.743 \\
\hline
\end{tabular}

Of the 140 implants inserted in the native bone at a period of 6 months, the peri-implant bone loss was $1 \pm 0.7 \mathrm{~mm}$ at the mesial level and $1 \pm 0.8 \mathrm{~mm}$ at the distal level.

Of the 72 implants placed in an allograft at a period of 6 months, the peri-implant bone loss was $0.8 \pm 0.8 \mathrm{~mm}$ at the mesial level and $0.8 \pm 0.7 \mathrm{~mm}$ at the distal level.

Of the 50 implants inserted in the native bone at a period of 12 months, the peri-implant bone loss was $0.95 \pm 0.5$ $\mathrm{mm}$ at the mesial level and $1.1 \pm 0.7 \mathrm{~mm}$ at the distal level.

Of the 23 implants placed in an allograft at a period of 12 months, the peri-implant bone loss was $1.2 \pm 0.9 \mathrm{~mm}$ at the mesial level and $1.25 \pm 0.8 \mathrm{~mm}$ at the distal level (Table 4).

Table 4. Peri-implant bone loss in the native bone and in the DFDBA.

\begin{tabular}{|c|c|c|c|c|c|}
\hline \multicolumn{2}{|c|}{-} & Rx 6 Més & Rx 6 Dis & Rx 12 Més & Rx 12 Dis \\
\hline \multirow{3}{*}{ Native bone } & $\mathrm{N}$ & 140 & 140 & 50 & 50 \\
\cline { 2 - 6 } & $\mathrm{Mean}(\mathrm{mm})$ & 0.9646 & 0.9771 & 0.9530 & 1.0690 \\
\cline { 2 - 6 } & $\mathrm{SD}(\mathrm{mm})$ & 0.6966 & 0.7760 & 0.5242 & 0.7155 \\
\hline \multirow{3}{*}{ DFDBA (300-500 $\mu \mathrm{m})$} & $\mathrm{N}$ & 72 & 72 & 23 & 23 \\
\cline { 2 - 6 } & $\mathrm{Mean}(\mathrm{mm})$ & 0.8493 & 0.8243 & 1.2174 & 1.2500 \\
\cline { 2 - 6 } & $\mathrm{SD}(\mathrm{mm})$ & 0.8046 & 0.7296 & 0.8595 & 0.8033 \\
\hline
\end{tabular}

Student's t-test allowed us to note that there was no statistically significant difference between the peri-implant bone loss for the implants placed in the native bone and in an allograft at a time point of 6 months, either at the mesial level $(p=0.303)$ or the distal level $(p=0.167)$. This same conclusion was observed at 12 months both at the mesial level $(p=$ $0.183)$ and the distal level ( $p=0.337)$ (Table 5 and Fig. 2). 


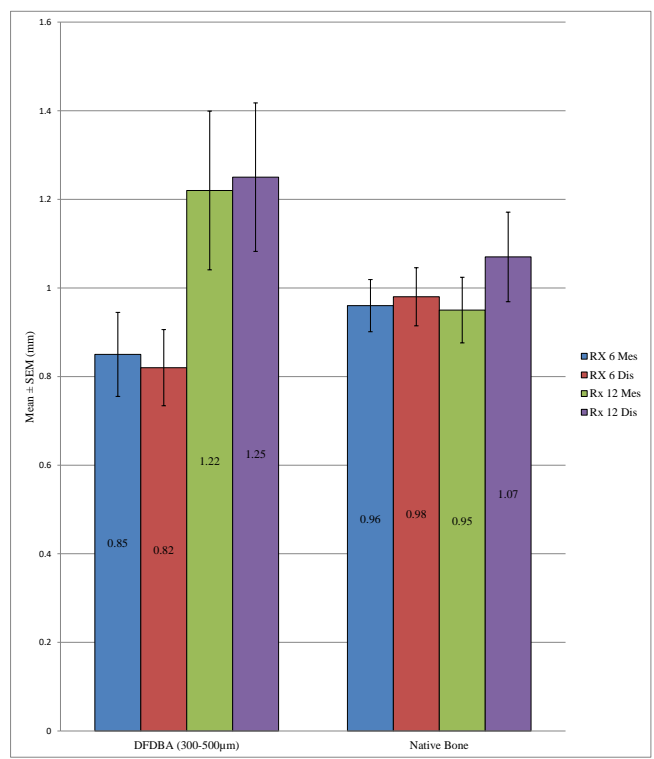

Fig. (2). Comparison of the peri-implant bone loss in the test group (DFDBA: 300-500 $\mu \mathrm{m}$ ) versus the control group (native bone).

Table 5. Comparison of peri-implant bone loss in DFDBA(300-500 $\mu \mathrm{m})$ versus in native bone.

\begin{tabular}{|c|c|c|c|c|c|}
\hline & - & $\mathbf{N}$ & Mean (mm) & SD (mm) & $P$-value \\
\hline \multirow{2}{*}{ Rx 6 Mes } & DFDBA $(300-500 \mu \mathrm{m})$ & 72 & 0.8493 & 0.8046 & \multirow{2}{*}{0.303} \\
\hline & Native bone & 140 & 0.9646 & 0.6966 & \\
\hline \multirow{2}{*}{ Rx 6 Dis } & DFDBA $(300-500 \mu \mathrm{m})$ & 72 & 0.8243 & 0.7296 & \multirow{2}{*}{0.167} \\
\hline & Native bone & 140 & 0.9771 & 0.7760 & \\
\hline \multirow{2}{*}{$\mathrm{Rx} 12 \mathrm{Mes}$} & DFDBA $(300-500 \mu \mathrm{m})$ & 23 & 1.2174 & 0.8595 & \multirow{2}{*}{0.183} \\
\hline & Native bone & 50 & 0.9530 & 0.5242 & \\
\hline \multirow{2}{*}{ Rx 12 Dis } & DFDBA $(300-500 \mu \mathrm{m})$ & 23 & 1.2500 & 0.8033 & \multirow{2}{*}{0.337} \\
\hline & Native bone & 50 & 1.0690 & 0.7155 & \\
\hline
\end{tabular}

\subsection{Comparison of the Peri-Implant Bone Loss in the Maxilla Versus Mandible}

We observed a statistically significant difference between the overall peri-implant bone loss in the mandible and in the maxilla at a time point of 6 months at the distal level $(p=0.032)$ and also at 12 months at both the mesial $(p=$ $0.004)$ and distal levels $(p=0.026)$. However, it was not possible to identify a difference at the mesial level at 6 months $(p=0.229)$ (Table 6 and Fig. 3).

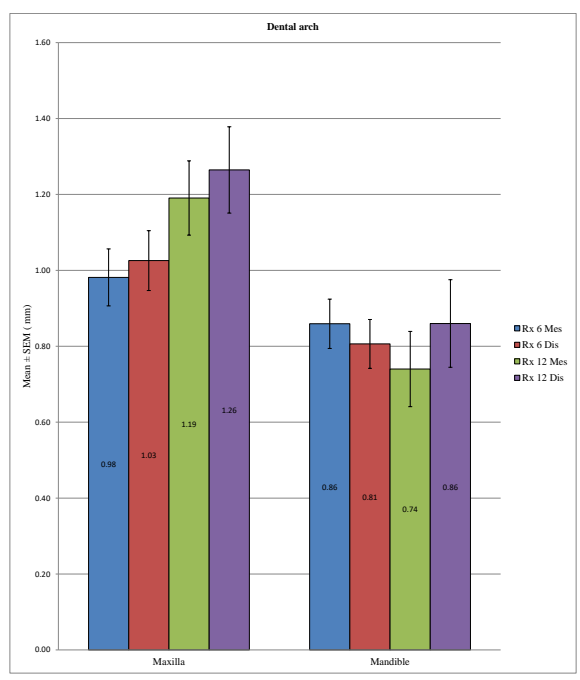

Fig. (3). Comparison in the global group (test and control groups taken together) of the peri-implant bone loss in the maxilla versus mandible. 
Table 6. Comparison in the global group (test and control groups taken together) of the peri-implant bone loss in the maxilla versus mandible.

\begin{tabular}{|c|c|c|c|c|c|}
\hline- & Dental Arch & $\mathbf{N}$ & Mean (mm) & SD (mm) & $P$-value \\
\hline \multirow{2}{*}{ Rx 6 Mes } & Maxilla & 115 & 0.9813 & 0.8049 & \multirow{2}{*}{0.229} \\
\hline & Mandible & 97 & 0.8593 & 0.6407 & \\
\hline \multirow{2}{*}{ Rx 6 Dis } & Maxilla & 115 & 1.0257 & 0.8454 & \multirow{2}{*}{$0.032 *$} \\
\hline & Mandible & 97 & 0.8062 & 0.6339 & \\
\hline \multirow{2}{*}{ Rx 12 Mes } & Maxilla & 48 & 1.1906 & 0.6776 & \multirow{2}{*}{$0.004 *$} \\
\hline & Mandible & 25 & 0.7400 & 0.4958 & \\
\hline \multirow{2}{*}{ Rx 12 Dis } & Maxilla & 48 & 1.2646 & 0.7872 & \multirow{2}{*}{$0.026^{*}$} \\
\hline & Mandible & 25 & 0.8600 & 0.5766 & \\
\hline
\end{tabular}

In the control group, the peri-implant bone loss was significantly different at the statistical level for the implants placed in the mandible versus in the maxilla, both at a 6 months at both the mesial $(p<0.001)$ and distal levels $(p$ $<0.001)$ and at 12 months at both the mesial $(p=0.010)$ and distal levels $(p=0.049)$. In the test group, a statistically significant difference could not be determined between the mandible and the maxilla at 12 months at the mesial $(p=$ $0.285)$ or distal level $(p=0.579)$ or at 6 months at the distal level $(p=0.207)$, unlike at the mesial level, with $p=0.040$. (Table 7; Figs. 4 and 5). Overall, the maxillary bone loss was greater than the mandibular bone loss, from an average of $0.2 \mathrm{~mm}$ at 6 months to $0.4 \mathrm{~mm}$ at 12 months.

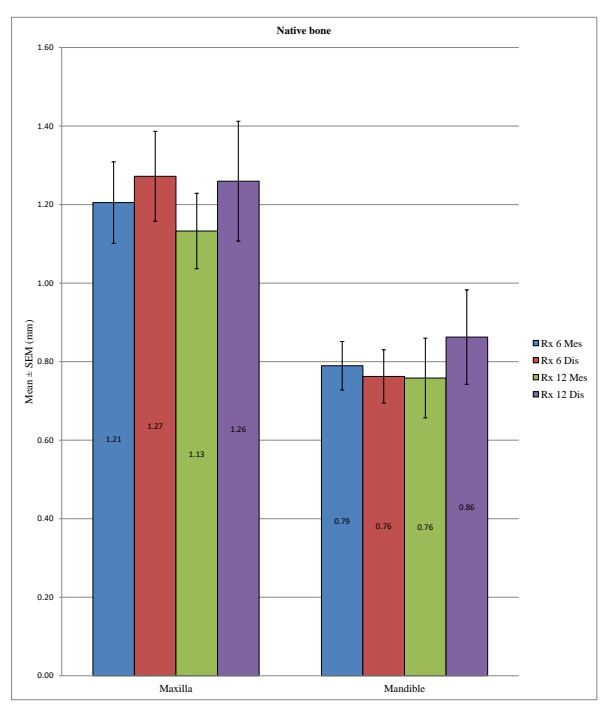

Fig. (4). Comparison in the control group of the peri-implant bone loss in the maxilla versus mandible.

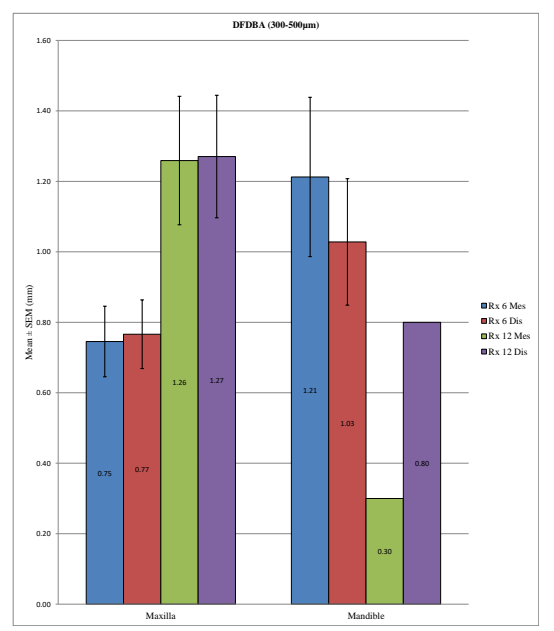

Fig. (5). CompaIn the control group, no statistically bone loss in the maxilla versus mandible. 
Table 7. Comparison in the control and test groups of the peri-implant bone loss in the maxilla versus mandible.

\begin{tabular}{|c|c|c|c|c|c|}
\hline Native Bone & Dental Arch & $\mathbf{N}$ & Mean (mm) & SD $(\mathbf{m m})$ & $P$-value \\
\hline \multirow{2}{*}{ Rx 6 Mes } & Maxilla & 59 & 1.2051 & 0.7968 & \multirow{2}{*}{$<0.001^{*}$} \\
\hline & Mandible & 81 & 0.7895 & 0.5560 & \\
\hline \multirow{2}{*}{$\mathrm{Rx} 6 \mathrm{Dis}$} & Maxilla & 59 & 1.2720 & 0.8799 & \multirow{2}{*}{$<0.001^{*}$} \\
\hline & Mandible & 81 & 0.7623 & 0.6115 & \\
\hline \multirow{2}{*}{ Rx 12 Mes } & Maxilla & 26 & 1.1327 & 0.4905 & \multirow{2}{*}{$0.010^{*}$} \\
\hline & Mandible & 24 & 0.7583 & 0.4977 & \\
\hline \multirow{2}{*}{ Rx 12 Dis } & Maxilla & 26 & 1.2596 & 0.7782 & \multirow{2}{*}{$0.049 *$} \\
\hline & Mandible & 24 & 0.8625 & 0.5889 & \\
\hline DFDBA $(300-500 \mu \mathrm{m})$ & Dental Arch & $\mathbf{N}$ & Mean (mm) & SD $(\mathbf{m m})$ & $P$-value \\
\hline \multirow{2}{*}{ Rx 6 Mes } & Maxilla & 56 & 0.7455 & 0.7504 & \multirow{2}{*}{$0.040^{*}$} \\
\hline & Mandible & 16 & 1.2125 & 0.9049 & \\
\hline \multirow{2}{*}{ Rx 6 Dis } & Maxilla & 56 & 0.7661 & 0.7289 & \multirow{2}{*}{0.207} \\
\hline & Mandible & 16 & 1.0281 & 0.7174 & \\
\hline \multirow{2}{*}{ Rx 12 Mes } & Maxilla & 22 & 1.2591 & 0.8556 & \multirow{2}{*}{0.285} \\
\hline & Mandible & 1 & 0.3000 & - & \\
\hline \multirow{2}{*}{ Rx 12 Dis } & Maxilla & 22 & 1.2705 & 0.8160 & \multirow{2}{*}{0.579} \\
\hline & Mandible & 1 & 0.8000 & - & \\
\hline
\end{tabular}

\subsection{Comparison of the Peri-Implant Bone Loss in a Patient With and Without Histories of Periodontitis}

No statistically significant difference could be demonstrated for the overall peri-implant bone loss between the patients with a history of periodontitis stabilized and patients without periodontal histories at 6 months at the mesial $(p=0.667)$ and distal levels $(p=0.480)$ or at 12 months at the mesial level $(p=0.075)$, except at 12 months at the distal level, with $p=0.027$ (Table 8 and Fig. 6).

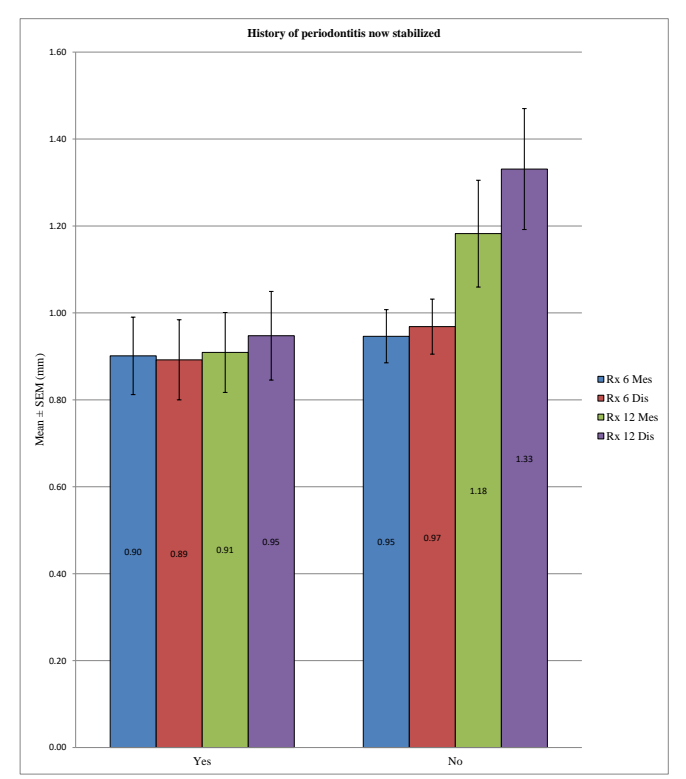

Fig. (6). Comparison in the global group (test and control groups taken together) of the peri-implant bone loss in the patients with a history of periodontitis versus those without.

Table 8. Comparison in the global group (test and control groups taken together) of the peri-implant bone loss in patients with a history of periodontitis now stabilized versus those without.

\begin{tabular}{|c|c|c|c|c|c|}
\hline- & History of Periodontitis now Stabilized & N & Mean (mm) & SD (mm) & $\boldsymbol{P}$-value \\
\hline \multirow{2}{*}{ Rx 6 Mes } & Yes & 87 & 0.9011 & 0.8319 & \multirow{2}{*}{0.667} \\
\cline { 2 - 6 } & No & 119 & 0.9462 & 0.6673 & \\
\hline \multirow{2}{*}{ Rx 6 Dis } & Yes & 87 & 0.8920 & 0.8601 & \multirow{2}{*}{0.480} \\
\cline { 2 - 7 } & No & 119 & 0.9685 & 0.6910 & \\
\hline
\end{tabular}




\begin{tabular}{|c|c|c|c|c|c|}
\hline- & History of Periodontitis now Stabilized & N & Mean $(\mathbf{m m})$ & SD $(\mathbf{m m})$ & $\boldsymbol{P}$-value \\
\hline \multirow{2}{*}{ Rx 12 Mes } & Yes & 39 & 0.9090 & 0.5742 & \multirow{2}{*}{0.075} \\
\cline { 2 - 6 } & No & 34 & 1.1824 & 0.7162 & \\
\hline \multirow{2}{*}{ Rx 12 Dis } & Yes & 39 & 0.9474 & 0.6367 & \multirow{2}{*}{$0.027 *$} \\
\cline { 2 - 6 } & No & 34 & 1.3309 & 0.8113 & \\
\hline
\end{tabular}

In the control group, no statistically significant difference was found between the bone loss in patients with a history of periodontitis now stabilized compared to patients without periodontal histories after 6 months at the mesial $(p=0.184)$ and distal levels $(p=0.562)$ or after 12 months at the mesial $(p=0.579)$ and distal levels $(p=0.436)$. In the test group, the difference in peri-implant bone loss was statistically significant between these two groups of patients mentioned above at 6 months at the mesial $(p=0.018)$ and distal levels $(p=0.033)$ or at 12 months at the distal level $(p=0.010)$, unlike at the mesial level, with $p=0.081$. (Table 9; Figs. 7 and 8)

Table 9. Comparison in the control and test groups of the peri-implant bone loss in patients with a history of periodontitis now stabilized versus those without.

\begin{tabular}{|c|c|c|c|c|c|}
\hline Native Bone & History of Periodontitis now Stabilized & $\mathbf{N}$ & Mean (mm) & SD (mm) & $P$-value \\
\hline \multirow{2}{*}{ Rx 6 Mes } & Yes & 56 & 1.0714 & 0.8653 & \multirow{2}{*}{0.184} \\
\hline & No & 78 & 0.8955 & 0.5506 & \\
\hline \multirow{2}{*}{ Rx 6 Dis } & Yes & 56 & 1.0455 & 0.9386 & \multirow{2}{*}{0.562} \\
\hline & No & 78 & 0.9609 & 0.6486 & \\
\hline \multirow{2}{*}{ Rx 12 Mes } & Yes & 28 & 0.9161 & 0.5688 & \multirow{2}{*}{0.579} \\
\hline & No & 22 & 1.0000 & 0.4701 & \\
\hline \multirow{2}{*}{$\mathrm{Rx} 12 \mathrm{Dis}$} & Yes & 28 & 0.9982 & 0.6910 & \multirow{2}{*}{0.436} \\
\hline & No & 22 & 1.1591 & 0.7519 & \\
\hline DFDBA $(300-500 \mu \mathrm{m})$ & History of periodontitis now stabilized & $\mathbf{N}$ & Mean $(\mathbf{m m})$ & SD $(\mathbf{m m})$ & $P$-value \\
\hline \multirow{2}{*}{ Rx 6 Mes } & Yes & 31 & 0.5935 & 0.6777 & \multirow{2}{*}{$0.018^{*}$} \\
\hline & No & 41 & 1.0427 & 0.8459 & \\
\hline \multirow{2}{*}{ Rx 6 Dis } & Yes & 31 & 0.6145 & 0.6180 & \multirow{2}{*}{$0.033 *$} \\
\hline & No & 41 & 0.9829 & 0.7737 & \\
\hline \multirow{2}{*}{$\mathrm{Rx} 12 \mathrm{Mes}$} & Yes & 11 & 0.8909 & 0.6156 & \multirow{2}{*}{0.081} \\
\hline & No & 12 & 1.5167 & 0.9637 & \\
\hline \multirow{2}{*}{ Rx 12 Dis } & Yes & 11 & 0.8182 & 0.4750 & \multirow{2}{*}{$0.010^{*}$} \\
\hline & No & 12 & 1,6458 & 0,8532 & \\
\hline
\end{tabular}

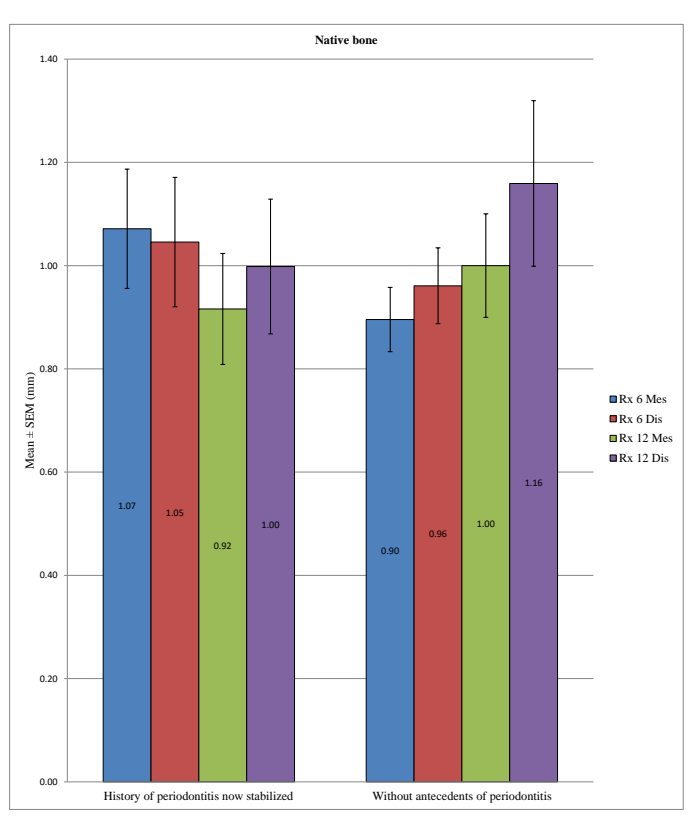

Fig. (7). Comparison in the control group of the peri-implant bone loss in the patients with a history of periodontitis versus those without. 


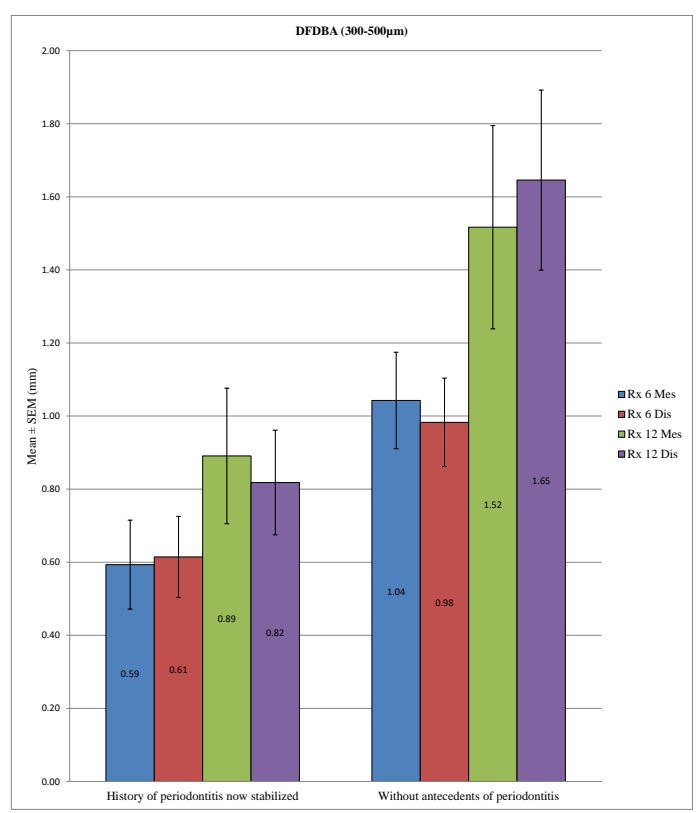

Fig. (8). Comparison in the test group of the peri-implant bone loss in the patients with a history of periodontitis versus those without.

Regardless of the test group, we observed no significant difference between the two groups of patients.

\subsection{Comparison of the Peri-Implant Bone Loss in Unitary Edentation Versus Partial Edentation Versus Total Edentation}

ANOVA allowed us to find a statistically significant difference in overall peri-implant bone loss among the various types of edentation at 6 months at the mesial $(p<0.001)$ and distal levels $(p<0.001)$ and also at 12 months at the mesial $(p<0.001)$ and distal levels $(p<0.001)$. More precisely, at 6 months, we noted at the mesial level differences between the unitary and total edentation $(p<0.001)$ and between the partial and total edentation $(p<0.001)$ but no difference between the unitary and partial edentation $(p=0.342)$. At 6 months, at the distal level, there was a difference between the unitary and partial edentation $(p=0.004)$, between the unitary and total edentation $(p<0.001)$, and between the partial and total edentation $p=0.016$. Moreover, at 12 months, we noted at the mesial and distal levels the absence of differences between the unitary and partial edentation $(p=1)$ and a difference between the unitary and total edentation $(p<0.001)$ and between the partial and total edentation $(p<0.001)$ (Table 10 and Fig. 9).

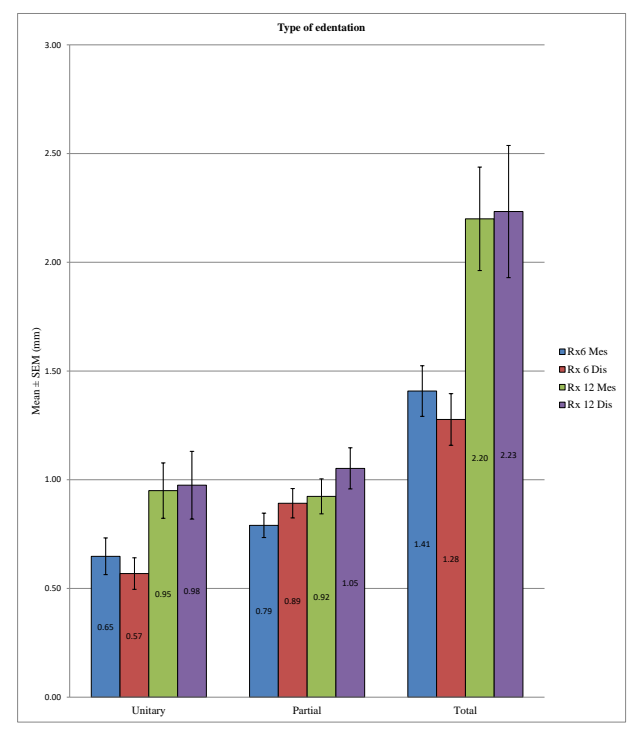

Fig. (9). Comparison in the global group (test and control groups taken together) of the peri-implant bone loss in unitary edentation versus partial edentation versus total edentation. 
Table 10. Comparison in the global group (test and control groups taken together) of the peri-implant bone loss in unitary edentation versus partial edentation versus total edentation.

\begin{tabular}{|c|c|c|c|c|c|c|}
\hline- & Type of Edentation & $\mathbf{N}$ & Mean $(\mathrm{mm})$ & SD (mm) & $P$-value ANOVA & Pairs $\boldsymbol{P}$-value: Games Howell/Bonferroni \\
\hline \multirow{3}{*}{ Rx 6 Mes } & Unitary & 46 & 0.6478 & 0.5718 & \multirow{3}{*}{$<0.001$} & U-P: 0.342 \\
\hline & Partial & 109 & 0.7904 & 0.5880 & & U-T: $<0.001 *$ \\
\hline & Total & 57 & 1.4079 & 0.8782 & & P-T: $<0.001^{*}$ \\
\hline \multirow{3}{*}{$\mathrm{Rx} 6 \mathrm{Dis}$} & Unitary & 46 & 0.5685 & 0.4908 & \multirow{3}{*}{$<0.001$} & U-P: $0.004 *$ \\
\hline & Partial & 109 & 0.8917 & 0.7059 & & U-T: $<0.001 *$ \\
\hline & Total & 57 & 1.2772 & 0.8954 & & P-T: $0.016^{*}$ \\
\hline \multirow{3}{*}{ Rx 12 Mes } & Unitary & 22 & 0.9500 & 0.5966 & \multirow{3}{*}{$<0.001$} & U-P: 1.000 \\
\hline & Partial & 45 & 0.9233 & 0.5389 & & U-T: $<0.001 *$ \\
\hline & Total & 6 & 2.2000 & 0.5831 & & P-T: $<0.001 *$ \\
\hline \multirow{3}{*}{ Rx 12 Dis } & Unitary & 22 & 0.9750 & 0.7299 & \multirow{3}{*}{$<0.001$} & U-P: 1.000 \\
\hline & Partial & 45 & 1.0522 & 0.6348 & & U-T: $<0.001 *$ \\
\hline & Total & 6 & 2.2333 & 0.7448 & & P-T: $<0.001 *$ \\
\hline
\end{tabular}

In the control group, there was a statistically significant difference in peri-implant bone loss among the three types of edentation at 6 months $(p=0.001)$ at the mesial and distal levels $(p<0.001)$, but such a difference was not observed at 12 months at the mesial $(p=0.536)$ and distal levels $(p=0.416)$. More specifically, at 6 months, we observed a difference between the unitary and partial edentation at the mesial level $(p=0.019)$, as well as at the distal level $(p<0.001)$, and between the unitary and total edentation at the mesial $(p=0.001)$ and distal levels $(p=0.008)$, but between the partial and total edentation, differences could not be found at the mesial $(p=0.058)$ or distal level $(p=$ 0.613). In the test group, we note a statistically significant difference in peri-implant bone loss among the different types of edentation at 6 months at the mesial $(p<0.001)$ and distal levels $(p<0.001)$ and also at 12 months at the mesial $(p=0.001)$ and distal levels $(p<0.001)$. More precisely, at 6 months, we found differences between the unitary and total edentation at the mesial $(p=0.028)$ and distal levels $(p=0.006)$ and between the partial and total edentation at the mesial $(p<0.001)$ and distal levels $(p<0.001)$, but we did not observe differences between the partial and unitary edentation at mesial $(p=0.514)$ or distal level $(p=1)$. At 12 months, we found differences between the unitary and total edentation at the mesial $(p=0.037)$ and distal levels $(p=0.007)$ and between the partial and total edentation at the mesial $(p<0.001)$ and distal levels $(p<0.001)$, but we did not note differences between the partial and unitary edentation at the mesial $(p=0.697)$ or distal levels $(p=1)$ (Table 11; Figs. 10 and 11).

Table 11. Comparison in the control and test groups of the peri-implant bone loss in unitary edentation versus partial edentation versus total edentation.

\begin{tabular}{|c|c|c|c|c|c|c|}
\hline Native Bone & Type of Edentation & $\mathbf{N}$ & Mean (mm) & SD (mm) & $P$-value ANOVA & Pairs $P$-value: Games Howell/Bonferroni \\
\hline \multirow{3}{*}{ Rx 6 Mes } & Unitary & 37 & 0.6459 & 0.5650 & \multirow{3}{*}{$<0.001$} & U-P: $0.019^{*}$ \\
\hline & Partial & 76 & 0.9599 & 0.5676 & & U-T: $0.001^{*}$ \\
\hline & Total & 27 & 1.4148 & 0.9315 & & P-T: 0.058 \\
\hline \multirow{3}{*}{$\mathrm{Rx} 6 \mathrm{Dis}$} & Unitary & 37 & 0.5797 & 0.4861 & \multirow{3}{*}{$<0.001$} & U-P: $<0.001 *$ \\
\hline & Partial & 76 & 1.0658 & 0.7104 & & U-T: $0.008^{*}$ \\
\hline & Total & 27 & 1.2722 & 1.0478 & & P-T: 0.613 \\
\hline \multirow{3}{*}{ Rx 12 Mes } & Unitary & 17 & 0.8882 & 0.5808 & \multirow{3}{*}{0.536} & \multirow{3}{*}{-} \\
\hline & Partial & 33 & 0.9864 & 0.4986 & & \\
\hline & Total & 0 & & & & \\
\hline \multirow{3}{*}{ Rx 12 Dis } & Unitary & 17 & 0.9529 & 0.7954 & \multirow{3}{*}{0.416} & \multirow{3}{*}{-} \\
\hline & Partial & 33 & 1.1288 & 0.6758 & & \\
\hline & Total & 0 & & & & \\
\hline $\begin{array}{c}\text { DFDBA (300-500 } \\
\mu \mathrm{m})\end{array}$ & Type of edentation & $\mathbf{N}$ & Mean (mm) & SD (mm) & $P$-value ANOVA & Pairs $P$-value: Games Howell/Bonferroni \\
\hline \multirow{3}{*}{ Rx 6 Mes } & Unitary & 9 & 0.6556 & 0.6346 & \multirow{3}{*}{$<0.001$} & U-P: 0.514 \\
\hline & Partial & 33 & 0.4000 & 0.4316 & & U-T: $0.028^{*}$ \\
\hline & Total & 30 & 1.4017 & 0.8434 & & P-T: $<0.001^{*}$ \\
\hline
\end{tabular}




\begin{tabular}{|c|c|c|c|c|c|c|}
\hline Native Bone & Type of Edentation & $\mathbf{N}$ & Mean (mm) & SD (mm) & $P$-value ANOVA & Pairs $P$-value: Games Howell/Bonferroni \\
\hline \multirow{3}{*}{$\mathrm{Rx} 6 \mathrm{Dis}$} & Unitary & 9 & 0.5222 & 0.5374 & \multirow{3}{*}{$<0.001$} & U-P: 1.000 \\
\hline & Partial & 33 & 0.4909 & 0.5113 & & U-T: $0.006^{*}$ \\
\hline & Total & 30 & 1.2817 & 0.7509 & & P-T: $<0.001^{*}$ \\
\hline \multirow{3}{*}{$\mathrm{Rx} 12 \mathrm{Mes}$} & Unitary & 5 & 1.1600 & 0.6693 & \multirow{3}{*}{0.001} & U-P: 0.697 \\
\hline & Partial & 12 & 0.7500 & 0.6274 & & U-T: $0.037^{*}$ \\
\hline & Total & 6 & 2.2000 & 0.5831 & & P-T: $<0.001^{*}$ \\
\hline \multirow{3}{*}{$\mathrm{Rx} 12 \mathrm{Dis}$} & Unitary & 5 & 1.0500 & 0.5074 & \multirow{3}{*}{$<0.001$} & U-P: 1.000 \\
\hline & Partial & 12 & 0.8417 & 0.4660 & & U-T: $0.007^{*}$ \\
\hline & Total & 6 & 2.2333 & 0.7448 & & P-T: $<0.001^{*}$ \\
\hline
\end{tabular}

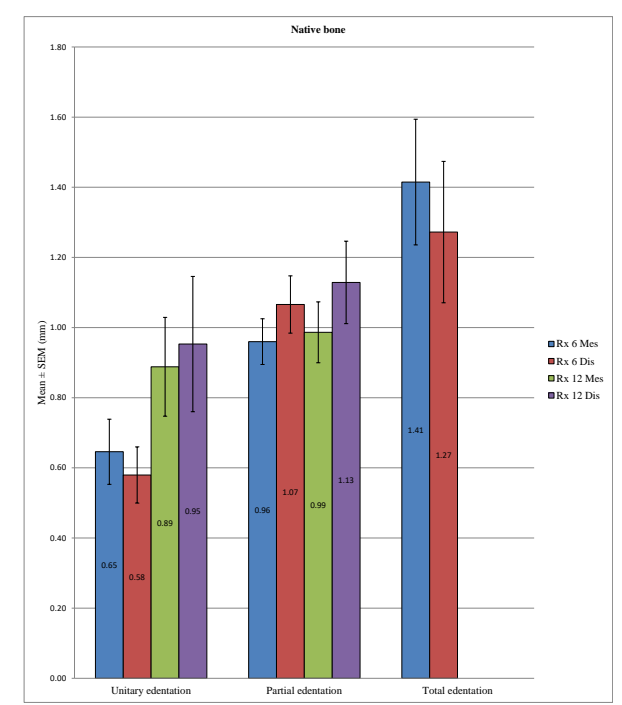

Fig. (10). Comparison in the control group of the peri-implant bone loss in unitary edentation versus partial edentation versus total edentation.

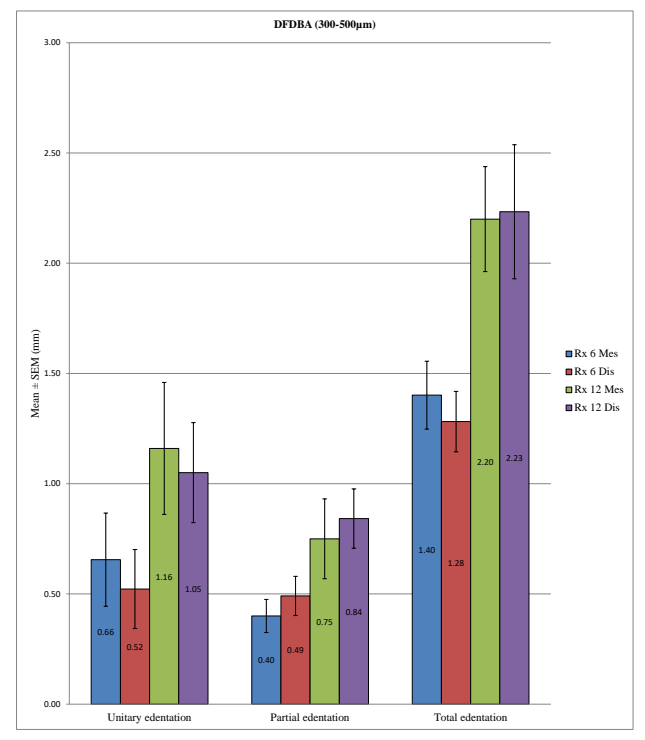

Fig. (11). Comparison in the test group of the peri-implant bone loss in unitary edentation versus partial edentation versus total edentation.

Despite some exceptions, the general trend was that there is a significant difference in bone loss between the unitary and total edentation (difference on average of $0.7 \mathrm{~mm}$ at 6 months and $1.2 \mathrm{~mm}$ at 12 months) and between the partial and total edentation (difference on average of $0.5 \mathrm{~mm}$ at 6 months and $1.2 \mathrm{~mm}$ at 12 months) but no differences between the partial and unitary areas (Table 12). 
Table 12. Summary of the results.

\begin{tabular}{|c|c|}
\hline \multicolumn{2}{|c|}{ Peri-Implant Bone Loss } \\
\hline DFDBA (300-500 $\boldsymbol{\mu m})$ & Native bone \\
\hline 6 months: $0.83 \pm 0.77 \mathrm{~mm} / 12$ months: $1.23 \pm 0.83 \mathrm{~mm}$ & 6 months: $0.97 \pm 0.74 \mathrm{~mm} / 12$ months: $1.01 \pm 0.62 \mathrm{~mm}$ \\
\hline \multicolumn{2}{|c|}{ No significant difference $(p>0.05)$} \\
\hline \multicolumn{2}{|c|}{ With/without history of periodontitis } \\
\hline No significant difference $(p>0.05)$ \\
\hline \multicolumn{2}{|c|}{ Maxilla/Mandible } \\
\hline Significant difference $(p<0.05):$ maxilla $>$ mandible \\
\hline \multicolumn{2}{|c|}{ Type of edentation } \\
\hline Significant difference $(p<0.05)$ : total $>$ partial = unitary
\end{tabular}

\section{DISCUSSION}

It is difficult to compare the results of this study with those of other studies because there have been few studies of implant behavior in bone grafts and because there is a diversity of biomaterials and techniques used for alveolar preservation. Our study was focused on the peri-implant bone loss as a criterion of success. Then, the discussion is concentrated on the comparison of peri-implant bone loss in our study and in the other studies with different types of post-extraction alveolar bone conservation techniques.

According to the study by Barone et al. in 2012 [38], the average peri-implant bone loss at 3 years of follow-up was $1.02 \pm 0.3 \mathrm{~mm}$ for the group without alveolar conservation and $1.00 \pm 0.2 \mathrm{~mm}$ for the group with tooth sockets preserved using xenograft (pig bone). Furthermore, the authors did not observe significant differences in the marginal bone loss between the two groups at 1 year, 2 years or 3 years.

Crespi et al. compared in 2009 [39] the peri-implant bone loss with three biomaterials: Magnesium enriched in Hydroxyapatite (MHA), Calcium Sulfate (CS) and a xenograft (Pig Bone = PB). It emerged that there was no statistically significant difference at level of the bone loss at either the mesial or distal level among the groups after a period of 24 months. The average peri-implant bone loss after 24 months was $0.21 \pm 0.09 \mathrm{~mm}$ for the MHA group, 0.13 $\pm 0.09 \mathrm{~mm}$ for the CS group, and $0.16 \pm 0.08 \mathrm{~mm}$ for the PB group.

Patel et al. performed in 2012 [40] implant placement in tooth sockets preserved with synthetic bone graft (Straumann Bone Ceramic $=$ SBC) or xenograft (from Bovine Bone $=$ DBBM) and a barrier of collagen. A radiological assessment was also performed. At one year after loading, the authors did not observe any statistically significant differences in a peri-implant bone loss at the mesial and distal levels. The average bone loss after 1 year was $3.58 \pm 1.02$ $\mathrm{mm}$ at the mesial level and $3.28 \pm 1.03 \mathrm{~mm}$ at the distal level for the SBC group and $3.71 \pm 0.77 \mathrm{~mm}$ at the mesial level and $3.58 \pm 0.78 \mathrm{~mm}$ at the distal level for the DDBM group.

Block et al. in 2002 [41] placed 22 implants, of which 3 were inserted immediately after the extraction of singlerooted tooth with a human mineralized cancellous bone complement and the remainder of which were placed in a tooth socket preserved with an allograft (human mineralized cancellous bone). The radiological measurements at 4 months after the implant placement revealed an average bone loss of $0.51 \pm 0.41 \mathrm{~mm}$ at the mesial level and $0.48 \pm 0.53 \mathrm{~mm}$ at the distal level.

Koutouzis et al. in a retrospective and radiological study [42], found that the average peri-implant bone loss at a period of 12 months of follow-up was $0.15 \pm 0.33 \mathrm{~mm}$ in the group that had alveolar bone conservation with an allograft (DFDBA) and $0.16 \pm 0.32 \mathrm{~mm}$ in the group without alveolar bone preservation with no significant difference.

These articles showed that there was no difference in the peri-implant bone losses between tooth sockets preserved with different biomaterials and with native bone.

In our study including 247 implants in which a part was inserted into native bone and the remainder within a tooth socket preserved with DFDBA 300-500 $\mu \mathrm{m}$ and platelet concentrates, no statistically significant differences were found after radiological evaluation of the peri-implant bone loss at 6 months and 12 months at both the mesial and distal levels. These results were similar to those reported in some previous studies [38 - 42] but different from those cited in the study of Theofilos Koutouzis et al. [42], in which DFDBA was used as an alveolar filling material. However, in the latter study, tooth sockets were covered with collagen membranes, and the implants had a design of type "platform switching" that was supposed to reduce marginal bone loss [42]. Regarding differences in the protocol of alveolar 
preservation and type of implant, it is difficult to compare them rigorously with our study. We observed a significant difference between maxillary and mandibular bone loss for the control group; however, such a difference could not be noted in the test group except at the mesial level at 6 months. In the study by Theofilos Koutouzis et al. [42], no significant differences were found for maxillary or mandibular bone loss, unlike our results, in which the overall bone loss was significantly greater in the maxilla than in the mandible at 12 months on both sides and at 6 months only at the distal level.

Our results allowed us to note a lack of significant differences between peri-implant bone loss in the patients with a history of periodontitis now stabilized compared to patients without periodontal histories at 6 months and 12 months in the overall and control groups, while a difference existed in the test group (except at 12 months at the mesial level). However, in this test group, contrary to what one might think, the bone loss was greater in the patients without a history of periodontal disease. This finding can be explained by most of these implants being placed in patients who were completely toothless and therefore who experienced greater bone loss. In the study of Rinke et al. in 2011 [43], a significant association could not be found between the history of periodontitis and an increased prevalence of periimplantitis. In contrast, Karoussis et al. in 2003 [44] and Hardt et al. in 2002 [45] observed a significantly increased bone loss in patients with histories of periodontitis.

Concerning the sites of edentation, a global trend emerged because the peri-implant bone loss was significantly different between the unitary and total edentation (6 months: $0.6 \mathrm{~mm}$ versus $1.3 \mathrm{~mm} / 12 \mathrm{months}: 1 \mathrm{~mm}$ versus $2.2 \mathrm{~mm}$ ) and between the partial and total edentation ( 6 months: $0.8 \mathrm{~mm}$ versus $1.3 \mathrm{~mm} / 12$ months: $1 \mathrm{~mm}$ versus $2.2 \mathrm{~mm}$ ); however, there was no difference at the level of bone loss between the unitary and partial edentation $(6 \mathrm{months}: 0.6 \mathrm{~mm}$ versus $0.8 \mathrm{~mm} / 12$ months: $0.96 \mathrm{~mm}$ versus $0.98 \mathrm{~mm}$ ) except in the test group at 6 months. These findings were in agreement with those of previous studies, including Berglundh et al. in 2002 [7]. Fransson et al. in 2005 [46] noted that the bone loss was greater in total edentation compared to unitary edentation, in which the bone loss was minimal. They also hypothesized that implants placed in the partial and total edentation yielded the same results.

Oral biofilm with the accumulation of the microorganisms is the major factor responsible for the peri-implant bone loss. A predominance of anaerobic bacteria is present when there is a peri-implantitis. The microbiota associated with peri-implantitis is different from the one from the periodontitis. Indeed, the surroundings of the implant in titanium provide a different environment than a tooth and therefore the bacteria around the implants are different. The flora is similar between peri-implantitis and chronic periodontitis, but bacteria like Staphylococcus aureus, Enerobacteriaceae, Candida albicans are a frequent finding in peri-implantitis. If the amount of bacteria is too important, there will be an infection and so the biofilm must be removed with various techniques and adjuvants. Following several studies, the fully edentulous patients have a microbiota that has less pathogenic plaque compared with partially edentulous subjects $[12,14,15]$.

\section{CONCLUSION}

Considering the results of this study, we can conclude that the implants placed in tooth sockets preserved with a mix of particulated allogenic bone (DFDBA: 300-500 $\mu \mathrm{m}$ ) and platelet concentrates behave similarly to implants inserted in native bone regarding the peri-implant bone loss, and that peri-implant bone loss remains inferior to tolerated bone loss to be able to consider implant success.

\section{ETHICS APPROVAL AND CONSENT TO PARTICIPATE}

This study is approved by Ethics Committee of Erasme Hospital-ULB Approval P2013 / 296.

\section{HUMAN AND ANIMAL RIGHTS}

No animals were used in this research. All research procedures followed were in accordance with the ethical standards of the committee responsible for human experimentation (institutional and national), and with the Helsinki Declaration of 1975, as revised in 2008.

\section{CONSENT FOR PUBLICATION}

Written and informed consent was obtained from the patients.

\section{CONFLICT OF INTEREST}

The authors declare no conflict of interest, financial or otherwise. 


\section{ACKNOWLEDGEMENTS}

This study was performed at the Department of Dentistry - Oral and Maxillofacial Surgery - Orthodontics Stomatology, Hospital Erasme, ULB, Brussel, Belgium.

\section{REFERENCES}

[1] Albrektsson T, Zarb G, Worthington P, Eriksson AR. The long-term efficacy of currently used dental implants: A review and proposed criteria of success. Int J Oral Maxillofac Implants 1986; 1(1): 11-25.

[PMID: 3527955]

[2] Smith DE, Zarb GA. Criteria for success of osseointegrated endosseous implants. J Prosthet Dent 1989; 62(5): 567-72. [http://dx.doi.org/10.1016/0022-3913(89)90081-4] [PMID: 2691661]

[3] Papaspyridakos P, Chen C-J, Singh M, Weber H-P, Gallucci GO. Success criteria in implant dentistry: A systematic review. J Dent Res 2012; 91(3): 242-8. [http://dx.doi.org/10.1177/0022034511431252] [PMID: 22157097]

[4] Karoussis IK, Brägger U, Salvi GE, Bürgin W, Lang NP. Effect of implant design on survival and success rates of titanium oral implants: A 10-year prospective cohort study of the ITI Dental Implant System. Clin Oral Implants Res 2004; 15(1): 8-17. [http://dx.doi.org/10.1111/j.1600-0501.2004.00983.x] [PMID: 14731173]

[5] Lee C-T, Huang Y-W, Zhu L, Weltman R. Prevalences of peri-implantitis and peri-implant mucositis: Systematic review and meta-analysis. J Dent 2017; 62: 1-12. [http://dx.doi.org/10.1016/j.jdent.2017.04.011] [PMID: 28478213]

[6] Annibali S, Bignozzi I, La Monaca G, Cristalli MP. Usefulness of the aesthetic result as a success criterion for implant therapy: A review. Clin Implant Dent Relat Res 2012; 14(1): 3-40. [http://dx.doi.org/10.1111/j.1708-8208.2009.00234.x] [PMID: 19673953]

[7] Giovannoli J-L, Renvert S. Péri-implantites, Ed. Quintessence International, Paris, 2012; pp. 259.

[8] Corsalini M, Di Venere D, Stefanachi G, et al. Maxillary overdenture retained with an implant support CAD-CAM bar: A 4 years follow up case. Open Dent J 2017; 11: 247-56. [http://dx.doi.org/10.2174/1874210601711010247] [PMID: 28659995]

[9] Heitz-Mayfield LJA. Peri-implant diseases: Diagnosis and risk indicators. J Clin Periodontol 2008; 35(8)(Suppl): $292-304$. [http://dx.doi.org/10.1111/j.1600-051X.2008.01275.x] [PMID: 18724857]

[10] Quirynen M, De Soete M, van Steenberghe D. Infectious risks for oral implants: A review of the literature. Clin Oral Implants Res 2002; 13(1): 1-19. [http://dx.doi.org/10.1034/j.1600-0501.2002.130101.x] [PMID: 12005139]

[11] Marrone A, Lasserre J, Bercy P, Brecx MC. Prevalence and risk factors for peri-implant disease in Belgian adults. Clin Oral Implants Res 2013; 24(8): 934-40. [http://dx.doi.org/10.1111/j.1600-0501.2012.02476.x] [PMID: 22551347]

[12] Renvert S, Quirynen M. Risk indicators for peri-implantitis. A narrative review. Clin Oral Implants Res 2015; 26(Suppl. 11): 15-44. [http://dx.doi.org/10.1111/clr.12636] [PMID: 26385619]

[13] Zhou W, Han C, Li D, Li Y, Song Y, Zhao Y. Endodontic treatment of teeth induces retrograde peri-implantitis. Clin Oral Implants Res 2009; 20(12): 1326-32.

[http://dx.doi.org/10.1111/j.1600-0501.2009.01752.x] [PMID: 19709062]

[14] Isola G, Matarese G, Williams RC, et al. The effects of a desiccant agent in the treatment of chronic periodontitis: A randomized, controlled clinical trial. Clin Oral Investig 2018; 22(2): 791-800. [http://dx.doi.org/10.1007/s00784-017-2154-7] [PMID: 28624914]

[15] Matarese G, Ramaglia L, Cicciù M, Cordasco G, Isola G. The effects of diode laser therapy as an adjunct to scaling and root planing in the treatment of aggressive periodontitis: A 1-year randomized controlled clinical trial. Photomed Laser Surg 2017; 35(12): 702-9. [http://dx.doi.org/10.1089/pho.2017.4288] [PMID: 28945145]

[16] Van der Weijden F, Dell'Acqua F, Slot DE. Alveolar bone dimensional changes of post-extraction sockets in humans: A systematic review. J Clin Periodontol 2009; 36(12): 1048-58.

[http://dx.doi.org/10.1111/j.1600-051X.2009.01482.x] [PMID: 19929956]

[17] Araújo MG, Lindhe J. Socket grafting with the use of autologous bone: An experimental study in the dog. Clin Oral Implants Res 2011; 22(1): 9-13. [http://dx.doi.org/10.1111/j.1600-0501.2010.01937.x] [PMID: 21091539]

[18] Darby I, Chen ST, Buser D. Ridge preservation techniques for implant therapy. Int J Oral Maxillofac Implants 2009; 24(Suppl): 260-71. [PMID: 19885449]

[19] Vignoletti F, Matesanz P, Rodrigo D, Figuero E, Martin C, Sanz M. Surgical protocols for ridge preservation after tooth extraction. A systematic review. Clin Oral Implants Res 2012; 23(Suppl 5): 22-38. [http://dx.doi.org/10.1111/j.1600-0501.2011.02331.x] [PMID: 22211304] 
[20] Horváth A, Mardas N, Mezzomo LA, Needleman IG, Donos N. Alveolar ridge preservation. A systematic review. Clin Oral Investig 2013; 17(2): 341-63. [http://dx.doi.org/10.1007/s00784-012-0758-5] [PMID: 22814758]

[21] De Risi V, Clementini M, Vittorini G, Mannocci A, De Sanctis M. Alveolar ridge preservation techniques: A systematic review and metaanalysis of histological and histomorphometrical data. Clin Oral Implants Res 2015; 26(1): 50-68. [http://dx.doi.org/10.1111/clr.12288] [PMID: 27007188]

[22] Ten Heggeler JM, Slot DE, Van der Weijden GA. Effect of socket preservation therapies following tooth extraction in non-molar regions in humans: A systematic review. Clin Oral Implants Res 2011; 22(8): 779-88. [http://dx.doi.org/10.1111/j.1600-0501.2010.02064.x] [PMID: 21091540]

[23] Fernandes PG, Muglia VA, Reino DM, et al. Socket preservation therapy with acellular dermal matrix and mineralized bone allograft after tooth extraction in humans: A clinical and histomorphometric study. Int J Periodontics Restorative Dent 2016; 36(2): e16-25. [http://dx.doi.org/10.11607/prd.2307] [PMID: 26901306]

[24] Moghaddas H, Amjadi MR, Naghsh N. Clinical and biometrical evaluation of socket preservation using demineralized freeze-dried bone allograft with and without the palatal connective tissue as a biologic membrane. Dent Res J 2012; 9(6): 758-63. [PMID: 23559955]

[25] Iasella JM, Greenwell H, Miller RL, et al. Ridge preservation with freeze-dried bone allograft and a collagen membrane compared to extraction alone for implant site development: A clinical and histologic study in humans. J Periodontol 2003; 74(7): 990-9. [http://dx.doi.org/10.1902/jop.2003.74.7.990] [PMID: 12931761]

[26] Wood RA, Mealey BL. Histologic comparison of healing after tooth extraction with ridge preservation using mineralized versus demineralized freeze-dried bone allograft. J Periodontol 2012; 83(3): 329-36. [http://dx.doi.org/10.1902/jop.2011.110270] [PMID: 21749166]

[27] Froum S, Cho SC, Rosenberg E, Rohrer M, Tarnow D. Histological comparison of healing extraction sockets implanted with bioactive glass or demineralized freeze-dried bone allograft: A pilot study. J Periodontol 2002; 73(1): 94-102. [http://dx.doi.org/10.1902/jop.2002.73.1.94] [PMID: 11846205]

[28] Dohan DM, Choukroun J, Diss A, et al. Platelet-rich fibrin (PRF): A second-generation platelet concentrate. Part I: Technological concepts and evolution. Oral Surg Oral Med Oral Pathol Oral Radiol Endod 2006; 101(3): e37-44. [http://dx.doi.org/10.1016/j.tripleo.2005.07.008] [PMID: 16504849]

[29] Dohan DM, Choukroun J, Diss A, et al. Platelet-rich fibrin (PRF): A second-generation platelet concentrate. Part II: Platelet-related biologic features. Oral Surg Oral Med Oral Pathol Oral Radiol Endod 2006; 101(3): e45-50. [http://dx.doi.org/10.1016/j.tripleo.2005.07.009] [PMID: 16504850]

[30] Dohan DM, Choukroun J, Diss A, et al. Platelet-rich fibrin (PRF): A second-generation platelet concentrate. Part III: leucocyte activation: A new feature for platelet concentrates? Oral Surg Oral Med Oral Pathol Oral Radiol Endod 2006; 101(3): e51-5. [http://dx.doi.org/10.1016/j.tripleo.2005.07.010] [PMID: 16504851]

[31] Choukroun J, Diss A, Simonpieri A, et al. Platelet-rich fibrin (PRF): A second-generation platelet concentrate. Part IV: Clinical effects on tissue healing. Oral Surg Oral Med Oral Pathol Oral Radiol Endod 2006; 101(3): e56-60. [http://dx.doi.org/10.1016/j.tripleo.2005.07.011] [PMID: 16504852]

[32] Hom DB, Linzie BM, Huang TC. The healing effects of autologous platelet gel on acute human skin wounds. Arch Facial Plast Surg 2007; 9(3): 174-83. [http://dx.doi.org/10.1001/archfaci.9.3.174] [PMID: 17519207]

[33] Girish Rao S, Bhat P, Nagesh KS, et al. Bone regeneration in extraction sockets with autologous platelet rich fibrin gel. J Maxillofac Oral Surg 2013; 12(1): 11-6.

[http://dx.doi.org/10.1007/s12663-012-0370-x] [PMID: 24431807]

[34] Simon BI, Zatcoff AL, Kong JJ, et al. Clinical and histological comparison of extraction socket healing following the use of autologous platelet-rich fibrin matrix (prfm) to ridge preservation procedures employing demineralized freeze dried bone allograft material and membrane. Open Dent J 2009; 20: 92-9.

[http://dx.doi.org/10.2174/1874210600903010092] [PMID: 19543550]

[35] Del Fabbro M, Corbella S, Taschieri S, Francetti L, Weinstein R. Autologous platelet concentrate for post-extraction socket healing: A systematic review. Eur J Oral Implantology 2014; 7(4): 333-44. [PMID: 25422822]

[36] Hauser F, Gaydarov N, Badoud I, Vazquez L, Bernard JP, Ammann P. Clinical and histological evaluation of postextraction platelet-rich fibrin socket filling: A prospective randomized controlled study. Implant Dent 2013; 22(3): 295-303. [http://dx.doi.org/10.1097/ID.0b013e3182906eb3] [PMID: 23644909]

[37] Piemontese M, Aspriello SD, Rubini C, Ferrante L, Procaccini M. Treatment of periodontal intrabony defects with demineralized freeze-dried bone allograft in combination with platelet-rich plasma: A comparative clinical trial. J Periodontol 2008; 79(5): 802-10. [http://dx.doi.org/10.1902/jop.2008.070436] [PMID: 18454658]

[38] Barone A, Orlando B, Cingano L, Marconcini S, Derchi G, Covani U. A randomized clinical trial to evaluate and compare implants placed in augmented versus non-augmented extraction sockets: 3-year results. J Periodontol 2012; 83(7): 836-46. [http://dx.doi.org/10.1902/jop.2011.110205] [PMID: 22141358] 
[39] Crespi R, Capparè P, Gherlone E. Dental implants placed in extraction sites grafted with different bone substitutes: Radiographic evaluation at 24 months. J Periodontol 2009; 80(10): 1616-21. [http://dx.doi.org/10.1902/jop.2009.090156] [PMID: 19792851]

[40] Patel K, Mardas N, Donos N. Radiographic and clinical outcomes of implants placed in ridge preserved sites: A 12-month post-loading follow-up. Clin Oral Implants Res 2013; 24(6): 599-605. [http://dx.doi.org/10.1111/j.1600-0501.2012.02500.x] [PMID: 22672611]

[41] Block MS, Finger I, Lytle R. Human mineralized bone in extraction sites before implant placement: Preliminary results. J Am Dent Assoc 2002; 133(12): 1631-8.

[http://dx.doi.org/10.14219/jada.archive.2002.0112] [PMID: 12512662]

[42] Koutouzis T, Lundgren T. Crestal bone-level changes around implants placed in post-extraction sockets augmented with demineralized freeze-dried bone allograft: A retrospective radiographic study. J Periodontol 2010; 81(10): 1441-8. [http://dx.doi.org/10.1902/jop.2010.100175] [PMID: 20569171]

[43] Rinke S, Ohl S, Ziebolz D, Lange K, Eickholz P. Prevalence of periimplant disease in partially edentulous patients: A practice-based crosssectional study. Clin Oral Implants Res 2011; 22(8): 826-33. [http://dx.doi.org/10.1111/j.1600-0501.2010.02061.x] [PMID: 21198898]

[44] Karoussis IK, Salvi GE, Heitz-Mayfield LJA, Brägger U, Hämmerle CH, Lang NP. Long-term implant prognosis in patients with and without a history of chronic periodontitis: A 10-year prospective cohort study of the ITI Dental Implant System. Clin Oral Implants Res 2003; 14(3): 329-39. [http://dx.doi.org/10.1034/j.1600-0501.000.00934.x] [PMID: 12755783]

[45] Hardt CRE, Gröndahl K, Lekholm U, Wennström JL. Outcome of implant therapy in relation to experienced loss of periodontal bone support: A retrospective 5- year study. Clin Oral Implants Res 2002; 13(5): 488-94. [http://dx.doi.org/10.1034/j.1600-0501.2002.130507.x] [PMID: 12453125]

[46] Fransson C, Lekholm U, Jemt T, Berglundh T. Prevalence of subjects with progressive bone loss at implants. Clin Oral Implants Res 2005; 16(4): 440-6. [http://dx.doi.org/10.1111/j.1600-0501.2005.01137.x] [PMID: 16117768]

(C) 2018 Bui Quoc et al.

This is an open access article distributed under the terms of the Creative Commons Attribution 4.0 International Public License (CC-BY 4.0), a copy of which is available at: (https:/creativecommons.org/licenses/by/4.0/legalcode). This license permits unrestricted use, distribution, and reproduction in any medium, provided the original author and source are credited. 